\title{
Medical Care for Chronic-Phase Stroke in Japan
}

\author{
Naoyuki HATTORI, ${ }^{1}$ Teruyasu HiRAYAmA, ${ }^{1}$ and Yoichi KATAYAMA ${ }^{1}$ \\ ${ }^{1}$ Department of Neurological Surgery, Nihon University School of Medicine, Tokyo
}

\begin{abstract}
Stroke leaves serious neurological sequelae, which require long-term medical and social care, imposing financial and mental burdens on the patients and their families, and causing enormous losses to society. It is currently required that medical resources be used efficiently and the cost-effectiveness of treatment be analyzed carefully. We conducted a follow-up survey of stroke patients admitted to the hospital attached to our university in order to build a picture of the current status of chronic-phase stroke medical treatment. In total, 330 patients were analyzed in this study. We evaluated utility and medical cost at one year after onset. To investigate the relationship between activities of daily living (ADL) classified according to the modified Rankin scale (mRS) and quality of life (QOL), utility was calculated for each ADL level. Utility at 1 year post-onset for each mRS level was: ADL0, 0.89; ADL1, 0.79; ADL2, 0.65; ADL3, 0.58; ADL4, 0.36; and ADL5, 0.09. A significant correlation was seen between utility and mRS. Direct monthly medical costs at 1 year post-onset were 61,536 yen in the ADLO group and 383,444 yen in the ADL5 group, indicating that a worse ADL score required higher medical costs. Direct monthly costs were significantly different between ADL levels. This present study has clarified the QOL and medical costs of chronic-phase stroke patients, and many cost-utility analyses will be based on our data in the future in Japan.
\end{abstract}

Key words: chronic-phase stroke, medical cost, quality of life, utility

\section{Introduction}

Stroke patients are left with serious sequelae, requiring long-term medical treatment or care services. Heavy physical and mental burdens are placed on the patient and their family, and the financial loss incurred by society is also enormous. Also, from the perspective of cost effectiveness in the medical care of strokes, quality of life (QOL) evaluations and medical cost data relating to both acute- and chronicphase patients are essential. However, with no reports of long-term follow-up studies addressing QOL and medical costs in Japan, the status of chronic-phase medical treatment remains unclear. We are currently conducting a follow-up survey of stroke patients admitted to the hospital attached to this university in order to build a picture of the current status of chronic-phase stroke medical treatment. Here we report the primary study, which has been completed and has yielded major results that will be of use in the future medical treatment of strokes.

Received June 30, 2011; Accepted October 12, 2011

\section{Materials and Methods}

Subjects were inpatients admitted to the hospital attached to our university for stroke between 2006 and 2010. The inclusion criteria for the study were patient's age between 35 and 85 years, and interval between stroke and start of treatment of less than 72 hours. The exclusion criteria were patients with hemorrhage from brain tumors and patients with malignant neoplasms. Caregivers were relatives living with the patient (spouses, adult children, parents, adult siblings, or adult grandchildren), or else people considered to be near relatives who spent at least 24 hours a week with the patient.

This study was a prospective cohort study with a fixed follow-up period of 3 years. The primary study of subjects and caregivers was carried out 1 year following the onset of stroke. A secondary study will be carried out 2 years post-onset and a tertiary study at 3 years post-onset, which will mark the completion of the study. Here, we report only on the primary study. Patients who died during the period of the primary study or who could not be followed up because they could not be contacted were excluded. Data were collected by means of interviews with patients or caregivers, conducted by the attending doctors 
either directly or by telephone. Medical costs were calculated using in-patient and out-patient receipts from all medical institutions attended by the patient. Medical costs for patients receiving various different services under the care insurance system were calculated on the basis of the payment limit for the patient, determined according to the level of care.

Neurological outcome was evaluated directly at 1 year after onset. Activities of daily living (ADL) were scored at 6 levels using the modified Rankin scale (mRS) as follows: ADL0, no symptoms; ADL1, minor symptoms that do not interfere with lifestyle; ADL2, minor handicap leading to some restriction in lifestyle but not interfering with the capacity for independence; ADL3, moderate handicap that significantly restricts lifestyle and prevents a totally independent existence; ADL4, moderately severe handicap that clearly prevents an independent existence, but without requiring constant attention; and ADL5, severe handicap requiring constant attention night and day. Death was designated as ADL6.

Stroke patients often bear a long-term burden of physical and mental stress, and evaluation of QOL is important in chronic-phase treatment. Various methods are available to measure QOL, and this study evaluated utility as an indication of healthrelated QOL, which is widely used in medical economics. ${ }^{12)}$ Utility was scored on an interval scale ranging from 0 (death) to 1 (complete health). To investigate the relationship between ADL classified according to the mRS and QOL, utility was calculated for each ADL level. In the present study, QOL was evaluated from information given by the caregiver using the EQ-5D Japanese version. ${ }^{3)}$

Medical costs were divided into direct and indirect medical costs for calculation. Direct medical costs include costs of admission to general hospitals, rehabilitation clinics, and long-term care institutions. In Japan, these costs are all paid for by medical insurance. The entire Japanese population is enrolled in mandatory medical insurance without choice based on employment and residence, called "Health-insurance-for-all." There are two medical insurance systems in Japan. One is the "Social Insurance System" for those working at a company or office, and the other is the "National Health Insurance System" for those uncovered by the Social Insurance System. The percentages of medical fees to be paid by insured people are $30 \%$ for those aged 3 to 69 years and $10 \%$ for those aged 70 years and older.

Patients being cared for at home can receive services such as home nursing, home rehabilitation, helpers, bathing, or temporary care, and these costs are paid for by care insurance. The Japanese care insurance system is modeled on the German system and was introduced in 2000. The level of care needed by patients is divided into seven levels, from support level 1 to care level 5, and each level of care has a fixed allowance to cover the needs of the patient (support level 1 is 50,000 yen, care level 5 is 350,000 yen/month). Patients being cared for at home can make use of various different services within the limit of payment for their designated level of care. In the present study, services paid for by the care insurance are included in the direct costs.

Indirect costs are calculated as two types: productivity loss of the patient as a result of the disease; and productivity loss of the caregiver as a result of the burden of caregiving. Indirect costs were calculated on the basis of the estimated production loss of the patient and their family members who were responsible for nursing at home, using the Wages Census, a fundamental statistic of wages and salary structure (2009), and a survey on the employment conditions of older individuals. ${ }^{10)}$ The expected mean wage of the patient was used in place of the productivity loss, based on the mean monthly salary. For example, according to the Wages Census, the mean annual wage for all wage earners aged 65 years old is $3,361,400$ yen, including salary and special allowances. Hence, the mean monthly wage is thus 280,116 yen. According to a survey on employment conditions of older individuals, the employment rate for wage earners of the same age is $39.9 \%$. Based on these data, the expected mean monthly wage for individuals aged 65 years old was calculated as $111,766(=280,116 \times 0.399)$ yen .

The productivity loss of each nursing person (mostly a family member of the patient) after the patient's discharge was calculated on the basis of a conversion of the time cost to the wage in the labor market. For estimating the time needed for nursing, it was assumed that ADL1, ADL2, ADL3, ADL4, and ADL5 required the following nursing times: 3,094.9, $3,882.9,6,715.4,10,778.5$, and $14,015.8$ seconds, respectively, as given in the Report of Survey Program for Service Supply Indices. ${ }^{4)}$ The productivity loss of the nursing person was calculated using the nursing time, where the time wage $(2,663$ yen/hour) was calculated for all wage earners by dividing the mean annual wage $(4,705,700$ yen/year) derived from the Wages Census by the annual working time $(1,767$ hour/year) obtained from the time occupied in regular work and overtime work.

Statistical analyses were performed as follows. Correlations between ADL and utility were assessed using Spearman's correlation coefficient. Differences in medical costs between ADL levels were assessed by the Kruskal-Wallis test. Differences were regarded as significant if the $\mathrm{p}$ value was less than 
0.05 .

\section{Results}

A total of 400 patients with stroke were admitted to the hospital attached to our university between 2006 and 2010, of whom 350 met the requirements for inclusion in the present study. These patients were entered into the study, and follow up after 1 year was possible for 330 patients. The breakdown of definitive diagnoses was: cerebral infarct, 209 (63.3\%); intracerebral hemorrhage, 67 (20.3\%); and subarachnoid hemorrhage, 54 (16.4\%). Mean age was 66.1 years; sex was 185 (56.1\%) men, 145 (43.9\%) women (Table 1).

ADL at 1 year post-onset by mRS level was: ADL0, 47 (14.2\%); ADL1, 46 (13.9\%); ADL2, 61 (18.5\%);

Table 1 Characteristics of patients

\begin{tabular}{lrrr}
\hline \multicolumn{1}{c}{ Type of stroke } & $\begin{array}{c}\text { No. of } \\
\text { cases }\end{array}$ & $\begin{array}{c}\text { Mean age } \\
\text { (years) }^{*}\end{array}$ & $\begin{array}{c}\text { Sex } \\
\text { (men/women) }\end{array}$ \\
\hline Cerebral infarct & 209 & $67.1 \pm 8.26$ & $120 / 89$ \\
Intracerebral hemorrhage & 67 & $65.9 \pm 8.89$ & $39 / 28$ \\
Subarachnoid hemorrhage & 54 & $62.5 \pm 9.65$ & $26 / 28$ \\
\hline
\end{tabular}

${ }^{*}$ Mean value \pm standard deviation.
ADL3, 66 (20.0\%); ADL4, 65 (19.7\%); and ADL5, 45 (13.6\%). With regard to the living environment for each ADL group, many patients in the ADL0 group had returned to work, whereas many in the ADL5 group required hospitalization. In the other ADL groups, the proportion of patients requiring home care was high (Table 2).

Utility at 1 year post-onset for each mRS level was: ADL0, $0.89( \pm 0.11)$; ADL1, $0.79( \pm 0.08)$; ADL2, 0.65 $( \pm 0.07) ;$ ADL3, $0.58( \pm 0.06) ;$ ADL4, $0.36( \pm 0.07)$; and ADL5, $0.09( \pm 0.08)$. A significant correlation was seen between utility and mRS $(p<0.001)$ (Table 3).

Direct monthly medical costs at 1 year post-onset were 61,536 yen $( \pm 9,094.3)$ in the ADL0 group and 383,444 yen $( \pm 74,458.2)$ in the ADL5 group, indicating that a worse ADL score required higher medical costs. Direct monthly costs were significantly different between ADL levels ( $p<0.001$ ). Production loss of patients due to the disease was 76,096 yen/month in the ADL0 group, in which many patients were able to return to a working lifestyle. This was somewhat less than the 111,766 yen/month productivity loss of the ADL3, ADL4, and ADL5 groups. Productivity loss among caregivers was proportionately higher where home care was given, and was higher in the ADL3 and ADL4 groups, in which the total

Table 2 Living environments in the chronic period

\begin{tabular}{lcccccc}
\hline \multicolumn{1}{c}{ Living environments } & ADL0 & ADL1 & ADL2 & ADL3 & ADL4 & ADL5 \\
\hline Return to working lifestyle & $15(31.9)$ & $5(10.9)$ & $2(3.3)$ & 0 & 0 & 0 \\
Living at home requiring no nursing care & $32(68.1)$ & $29(63.0)$ & $3(4.9)$ & $1(1.5)$ & 0 \\
Living at home requiring nursing care & 0 & $6(13.0)$ & $28(45.9)$ & $25(37.9)$ & $20(30.8)$ & $6(13.3)$ \\
Requiring long-term stay in nursing home & 0 & $3(6.5)$ & $19(31.1)$ & $28(42.2)$ & $32(49.2)$ & $21(46.7)$ \\
Requiring admission into rehabilitation centers & 0 & $2(4.3)$ & $4(26.2)$ & $2(3.0)$ & $1(1.5)$ & 0 \\
Requiring hospitalization in general hospitals & 0 & $1(2.2)$ & $5(8.2)$ & $10(15.2)$ & $12(18.5)$ & $18(40.0)$ \\
\hline Total & 47 & 46 & 61 & 66 & 65 & 45 \\
\hline
\end{tabular}

Activities of daily living (ADL) were scored at 6 levels using the modified Rankin scale (see text). Values show number of cases (\%).

Table 3 Activities of daily living (ADL) and utility in the chronic period (1 year after onset)

\begin{tabular}{lllllrr}
\hline & ADL0 & ADL1 & ADL2 & ADL3 & ADL4 & ADL5 \\
\hline Mean value* & 0.890 & 0.797 & 0.650 & 0.588 & 0.363 & 0.092 \\
Unbiased variance & 0.013 & 0.007 & 0.006 & 0.004 & 0.005 & 0.006 \\
Standard deviation & 0.114 & 0.084 & 0.074 & 0.067 & 0.073 & 0.080 \\
Standard variation & 0.017 & 0.012 & 0.010 & 0.008 & 0.009 & 0.012 \\
Minimum value & 0.736 & 0.705 & 0.497 & 0.448 & 0.232 & -0.111 \\
Maximum value & 1.000 & 1.000 & 0.795 & 0.774 & 0.482 & 0.195 \\
Coefficient of variation & 0.128 & 0.106 & 0.114 & 0.113 & 0.202 & 0.872 \\
\hline
\end{tabular}

ADL were scored at 6 levels using the modified Rankin scale (see text). ${ }^{*} \mathrm{p}<0.001$ by Spearman's correlation coefficient. 
Table 4 Medical and nursing care cost in the chronic period (1 year after onset)

\begin{tabular}{lccr}
\hline & Direct medical cost & \multicolumn{2}{c}{ Indirect medical cost } \\
\cline { 3 - 4 } & & Production loss & Nursing cost \\
\hline ADL0 & $61,536 \pm 9,094.3$ & 76,096 & 0 \\
ADL1 & $131,891 \pm 9,475.9$ & 99,617 & 47,853 \\
ADL2 & $261,306 \pm 97,496.6$ & 108,101 & 43,847 \\
ADL3 & $318,387 \pm 55,177.5$ & 111,766 & 58,852 \\
ADL4 & $344,398 \pm 71,227.6$ & 111,766 & 73,498 \\
ADL5 & $383,444 \pm 74,458.2$ & 111,766 & 40,535 \\
\hline
\end{tabular}

Activities of daily living (ADL) were scored at 6 levels using the modified Rankin scale (see text). Values are presented as means or means \pm standard deviation (Japanese yen/month). ${ }^{*} \mathrm{p}<0.001$ by the Kruskal-Wallis test.

hours of nursing care were higher compared to other groups (Table 4).

\section{Discussion}

Medical care for patients following stroke comprises three phases: the acute phase, in which surgery or intravenous treatment may be performed as part of the therapeutic regimen (within 1 month after onset); the recovery phase, in which the aim is for functional recovery mainly through rehabilitation (from 1 to 3 months post-onset); and the chronic phase, in which the aim is to maintain function through home care or long-term hospitalization ( $\geq 3$ months postonset). Acute-phase hospitalization and treatment comes under the Diagnosis Procedure Combinationbased comprehensive payment system, which was introduced in 2003. Under this original Japanese system, payment is made on a per-day basis. Services such as surgery, anesthesia, and rehabilitation are paid for as before in a piecemeal fashion, but other in-patient treatment fees are standardized across the whole country through a comprehensive points system. The Ministry of Health, Labour and Welfare not only publicizes these medical costs, but also patient outcomes and the details of treatment, so that gaining an understanding of the current status of acute-phase treatment is not difficult.

Besides the physical difficulties, stroke patients often have to bear the burden of mental disorders over the long term, so the chronic phase requires treatment focusing on QOL. In addition to medical care such as medication or rehabilitation, treatment also includes care services such as home-helpers, nursing visits, and short-stay hospitalization. Just as in the acute phase, costs are high. Evaluation of chronic-phase treatment in terms of both medical costs and QOL is important not just from the point of view of doctors and families concerned with stroke treatment, but also from the perspective of medical policy.

In the present study, medical costs were divided for evaluation into direct medical costs, which include hospital charges, medicine costs, treatment, and rehabilitation, and indirect costs, which take into account production loss of the patient and the caregiver. Direct medical costs increase with deterioration of ADL. In ADL3 or over, in which patients are unable to live independently, these costs exceed 300,000 yen/month. Productivity loss for the patient is only slightly decreased in ADL0 and ADL1, in which many patients are able to return to a working lifestyle. Productivity loss for the caregiver was greatest in ADL3 and ADL4, in which many patients receive care at home and the number of hours of care is high. Overall medical costs, which are the sum of direct and indirect medical costs, were more than 450,000 yen/month in ADL3 or higher, in which patients are unable to live independently. Needless to say, increasing the number of patients with ADL that permits independent living will reduce the costs of the chronic phase.

In the present study, a number of uncertainties with respect to medical costs must be considered. Regarding productivity loss due to illness, many patients may have already retired by the time of stroke onset. Also, with regard to the productivity loss of caregivers, the time spent providing care and the number of people involved in care is uncertain. The number of caregivers was limited to one in the present study, so in families with many people involved in caregiving, the actual productivity loss is very likely to have been much greater. In the present study, direct medical costs were calculated using medical economical methods, and elaborating these methods will be a challenge for the future.

The present study evaluated QOL as a measure of patient outcome. QOL evaluation is meaningful, bearing in mind the specific nature of stroke treatment and changes in the medical environment of Japan. Stroke patients often suffer long-term mental stress, and the therapeutic objective has become improving the quality of everyday life rather than bringing about a cure or prolonging life. Also, information disclosure and respect for the right of selfdetermination are stressed in medical settings, so that the importance of QOL, an outcome that takes the patient's perspective, is recognized by society. Moreover, medical economic evaluation that takes into account QOL has become important in order to make effective use of limited medical resources.

Various attempts have been made to quantify QOL, and the present study used utility, which is 
Table 5 Scoring the EQ-5D descriptive system

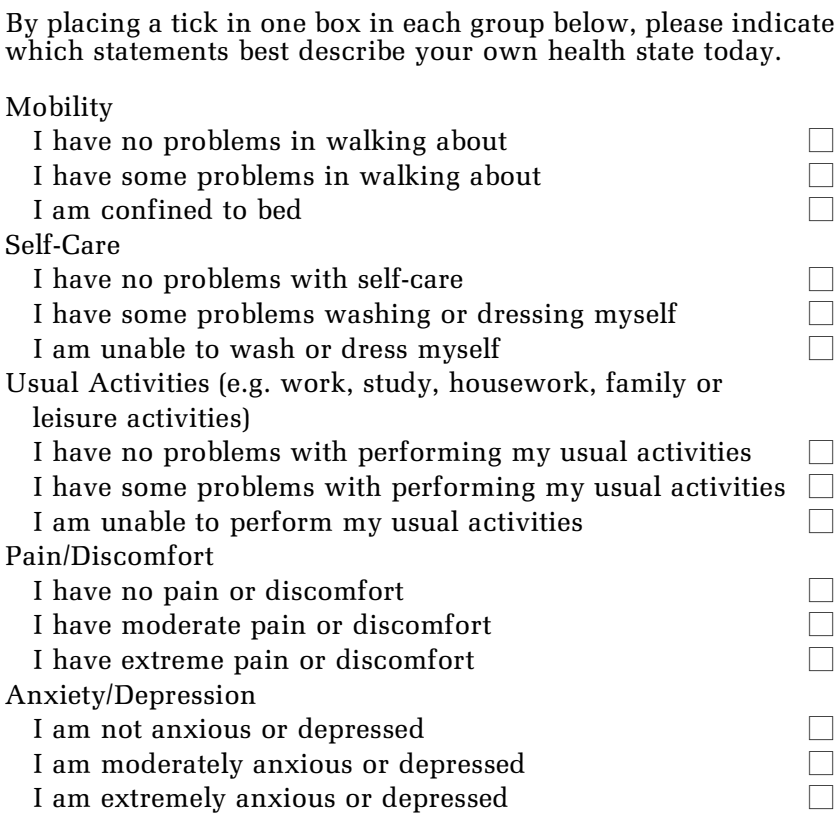

referred to as health-related QOL. This restricts QOL to physical activity and mental function (activity) for evaluation, and uses an interval scale from 0 (death) to 1 (complete health). The present study evaluated the QOL of the patient at the time of evaluation using the EQ-5D Japanese version, from information provided by the caregiver (Table 5). ${ }^{3)}$

The EQ-5D Japanese version takes QOL as consisting of five dimensions: mobility; self-care; usual activities; pain/discomfort; and anxiety/depression. Utility is calculated from the responses to five standardized questions, one for each of the five dimensions. For each question, the best response is selected from three alternatives. Utility is calculated from the responses using the Japanese version of the utility conversion table. We used evaluation by caregivers to calculate patient QOL in the present study. The advantage of utility is that the QOL of patients with different conditions can be evaluated using a single index. It is thus extremely useful for clinical decisions such as treatment selection, economic evaluations, or policymaking.

With the utility scores of chronic-phase stroke patients in the present study, utility was 0.89 in the ADL0 group and 0.79 in the ADL1 group (Table 3). Although ADL in these two groups is favorable, the utility scores are not high. ${ }^{2,16,17)}$ This is because many patients did not express satisfaction in the anxiety or pain/discomfort domains, and these patients would not have been identified in previous evaluations that used only ADL. At the same time,
Table 6 Cost per quality-adjusted life year (QALY) of medical interventions

\begin{tabular}{|c|c|c|}
\hline Intervention & $\begin{array}{l}\text { Cost per } \\
\text { QALY }\end{array}$ & Author (Year) \\
\hline $\begin{array}{l}\text { Elective surgery for asymptomatic, } \\
\text { unruptured, intracranial aneurysms }\end{array}$ & $\$ 24,200$ & $\begin{array}{l}\text { King et al. } \\
(1995)^{5)}\end{array}$ \\
\hline $\begin{array}{l}\text { Endovascular treatment for ruptured } \\
\text { intracranial aneurysms }\end{array}$ & $\$ 45,493$ & $\begin{array}{l}\text { Maud et al. } \\
(2009)^{9)}\end{array}$ \\
\hline $\begin{array}{l}\text { Neurosurgical treatments for } \\
\text { intracranial aneurysms }\end{array}$ & $\$ 41,769$ & $\begin{array}{l}\text { Maud et al. } \\
\quad(2009)^{9)}\end{array}$ \\
\hline $\begin{array}{l}\text { Gamma knife radiosurgery for multiple } \\
\text { metastatic brain tumors }\end{array}$ & $\$ 10,381$ & $\begin{array}{l}\text { Lee et al. } \\
(2009)^{8)}\end{array}$ \\
\hline $\begin{array}{l}\text { Radiosurgery for multiple metastatic } \\
\text { brain tumors }\end{array}$ & $\$ 17,622$ & $\begin{array}{l}\text { Lee et al. } \\
\qquad(2009)^{8)}\end{array}$ \\
\hline $\begin{array}{l}\text { Temozolomide for newly diagnosed } \\
\text { glioblastoma multiforme }\end{array}$ & $€ 37,361$ & $\begin{array}{l}\text { Lamers et al. } \\
\qquad(2008)^{7)}\end{array}$ \\
\hline $\begin{array}{l}\text { Intrathecal baclofen infusion for severe } \\
\text { spasticity }\end{array}$ & $\$ 19,570$ & $\begin{array}{l}\text { Sampson et al. } \\
(2002)^{15)}\end{array}$ \\
\hline
\end{tabular}

utility scores of bed-ridden patients were low, near to the level of death, indicating that these patients are under conditions of great physical and mental distress. For the medical economic analysis of cost utility, the evaluation index was quality-adjusted life years (QALY), which integrates quality and quantity of life. A QOL of utility 1 maintained for 1 year is 1 QALY, and the medical costs required to obtain 1 QALY are calculated for cost-utility analysis. The advantage of cost-utility analysis is that it crosses the divisions between different medical departments, allowing comparison of the medical economic effects of different medical interventions. Current medical services in Japan need to make effective use of limited medical resources, and so it is essential for medical policy-making to be able to evaluate different medical interventions on a level playing field for prioritization. In Western countries, there is generally a ceiling of $\$ 50,000 / Q A L Y$, up to which medical interventions can be considered from a medical economic standpoint. ${ }^{1,6,11)} \mathrm{A}$ partial cost-utility analysis of medical interventions in the other countries is shown in the Table $6 .^{5,7-9,15)}$ In Japan, reports to date recognize treatments of 6 million yen/QALY as giving excellent cost performance. ${ }^{13,14)}$

To date, few reports have undertaken cost-utility analysis of stroke treatment in Japan, the main reason being that there has been no accurate picture of chronic-phase stroke treatment. The present study has clarified the QOL and medical costs of chronicphase stroke patients, and we hope that many costutility analyses will be based on our data in the future. We are currently continuing with secondary and tertiary follow-up studies. Creation of a more accurate picture of chronic-phase stroke treatment should be possible from the data yielded by these studies and their analysis. 


\section{References}

1) EuroQol-a new facility for the measurement of health-related quality of life. The EuroQol Group. Health Policy 16: 199-208, 1990

2) Goldman L, Gordon DJ, Rifkind BM, Hulley SB, Detsky AS, Goodman DW, Kinosian B, Weinstein MC: Cost and health implications of cholesterol lowering. Circulation 85: 1960-1968, 1992

3) Ikegami N, Hukuhara S, Shimozuma K, Ikeda S (eds): [Handbook of Estimation for QOL]. Tokyo, IgakuShoin Ltd, 2001, pp 45-49 (Japanese)

4) Japan National Council of Social Welfare, Department of Welfare for Elderly Persons: [Report of Survey Program for Service Supply Indices]. Tokyo, Japan National Council of Social Welfare Press, 1995, pp 131-193 (Japanese)

5) King JT Jr, Glick HA, Mason TJ, Flamm ES: Elective surgery for asymptomatic, unruptured, intracranial aneurysms: a cost-effectiveness analysis. J Neurosurg 83: 403-412, 1995

6) King JT Jr, Tsevat J, Lave JR, Roberts MS: Willingness to pay for a quality-adjusted life year: Implications for societal health care resource allocation. Med Decis Making 25: 667-677, 2005

7) Lamers LM, Stupp R, van den Bent MJ, Al MJ, Gorlia T, Wasserfallen JB, Mittmann N, Jin Seung S, Crott R, Uyl-de Groot CA; EORTC 26981/22981 NCI-C CE3 Intergroup Study: Cost-effectiveness of temozolomide for the treatment of newly diagnosed glioblastoma multiforme: a report from the EORTC 26981/ 22981 NCI-C CE3 Intergroup Study. Cancer 112: 1337-1344, 2008

8) Lee WY, Cho DY, Lee HC, Chuang HC, Chen CC, Liu JL, Yang SN, Liang JA, Ho LH: Outcomes and costeffectiveness of gamma knife radiosurgery and whole brain radiotherapy for multiple metastatic brain tumors. J Clin Neurosci 16: 630-634, 2009
9) Maud A, Lakshminarayan K, Suri MF, Vazquez G, Lanzino G, Qureshi AI: Cost-effectiveness analysis of endovascular versus neurosurgical treatment for ruptured intracranial aneurysms in the United States. J Neurosurg 110: 880-886, 2009

10) Ministry of Health, Labour and Welfare, Policy Planning and Research Department, Wage Census: [Basic Survey on Wage Structure 2009]. Tokyo, Ministry of Finance Press, 2010, pp 2-101 (Japanese)

11) Nancy D, Parkin D: Does NICE have a cost-effectiveness threshold and what other factors influence its decisions? A binary choice analysis. Health Econ 13: 437-452, 2004

12) Nord E: Methods for quality adjustment of life years. Soc Sci Med 34: 559-569, 1992

13) Ohkusa Y: [Empirical research for the critical value of expenditure per QALY]. Iryo To Shakai 13: 121-130, 2003 (Japanese)

14) Ohkusa $Y$, Sugawara T: [Research for willingness to pay for one QALY gain]. Iryo To Shakai 16: 157-165, 2006 (Japanese)

15) Sampson FC, Hayward A, Evans G, Morton R, Collett B: Functional benefits and cost/benefit analysis of continuous intrathecal baclofen infusion for the management of severe spasticity. J Neurosurg 96: 1052-1057, 2002

16) Torrance GW: Measurement of health state utilities for economic appraisal. J Health Econ 5: 1-30, 1986

17) William A: Economics of coronary artery bypass grafting. BMJ 291: 326-329, 1985

Address reprint requests to: Naoyuki Hattori, MD, PhD, Department of Neurological Surgery, Nihon University School of Medicine, 30-1 Oyaguchi Kamimachi, Itabashi-ku, Tokyo 173-8610, Japan.

e-mail: naoyukihattori@me.com 